\title{
Promoting the Teachers' Development by Carrying Out International Education Cooperation Project
}

\author{
Xingzhi Li \\ Beijing Information Technology College, Beijing, 100015, China \\ E-mail:Lixingzhi@bitc.edu.cn
}

\begin{abstract}
The paper discusses the principle of promoting the teachers' development by carrying out international education cooperation project and implementing methods of training about how to make better use of foreign partners' resource. Suggestions are given to colleges to carry out overseas teacher training. Priority is given to send professional teachers overseas for training. Educational managers and English teachers are selected appropriately at the same time; more can be achieved by carrying out Sino-foreign international education projects to promote teachers' training; expand the scope of professional teachers' training step by step.
\end{abstract}

Keywords: international educational cooperation projects, overseas teachers' training

\section{Introduction about the international education cooperation projects and the overseas training of teachers of the college}

Beijing Information Technology College has a history of more than 20 years of running Sino-foreign international education cooperation projects. Since 1998, the college has successively cooperated with educational institutions from the United Kingdom, New Zealand, Singapore, Australia, Germany, Canada and other countries. The cooperated programs include: computer application, computer network technology, marketing, accounting, business English, mold design and manufacturing, electronic engineering, mechanical and electrical integration technology, computer software technology, etc. Through promoting the teachers' development by carrying out international education cooperation projects, the teachers' educational concept of internationalization and professional quality were improved, the internationalization level of the college has been improved.

\section{Principles to be followed in the implementation of overseas teacher training ${ }^{[1]}$}

\subsection{The principle of combining domestic and overseas training}

The experts from overseas partner college can be invited to provide on campus training for teachers who are going to teach the cooperative courses and administrators related about partner countries vocational education concept, curriculum implementation method of collaboration, cooperation course assessment method, quality control system, etc.

After domestic training, these trainees can be sent to the overseas partner campus to accept professional training about terms of curriculum implementation which focuses on interpretation course outline, teaching activity design and implementation of course evaluation, establishing and implementing of quality security system to help teachers get ready for back home cooperative courses teaching.

2.2 The principle of selecting and dispatching the most appropriate personnel to participate in the training

\subsubsection{The principle of relevance}

The overseas trainee's needs to be mainly selected the teachers who will participate in the cooperative course teaching. A small number of personnel from the teaching management department can also be arranged to participate in the training. 


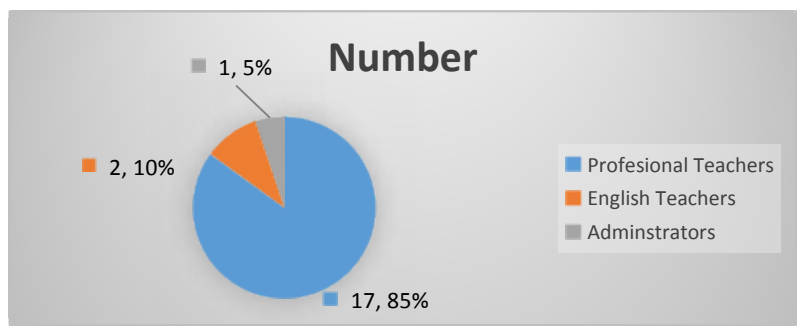

Diagram 1. Proportion of trainees

\subsubsection{The principle of meritocracy}

We can take the opportunity of in-college training to evaluate the teachers using test papers in English. Only qualified teachers are qualified to participate in the training, which is conducive to selecting the most appropriate personnel to participate in the teaching of international cooperation courses.

\subsubsection{The principle of not replacing professional teachers with English teachers}

As far as possible, professional teachers with good command of English are sent to be trained overseas, the professional teachers' English level can be improved along with the cooperative courses teaching. The bilingual teaching ability of professional teachers can be improved after some years of project running. This is the main purpose of running the international cooperation project in higher vocational college.

A few English teachers with high teaching level can also be selected to participate in the training, so as to let them know the teaching concept of international cooperation courses, and undertake the teaching task of English courses in cooperative classes after the training, so as to better promote the teaching work of international cooperation courses.

\subsection{Principle of cultivating professional teaching backbone through multiple dispatches}

In order to cultivate key teachers for cooperative courses teaching, a few good teachers can be sent out for training for the second time after they have taught cooperative course for three years or longer, the purpose is to cultivate trainers and quality controllers. After second training, in addition to continuing to undertake the cooperative curriculum teaching tasks,

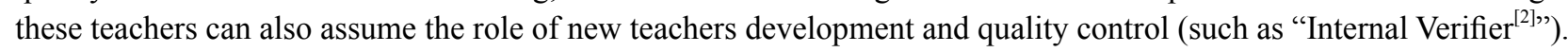

\section{Implementation of overseas training}

\subsection{Training content, training form and training goal setting}

The first time to send teachers abroad for a four-week training, the English training can be arranged for first two weeks, professional training can be arranged for the second two weeks. From the second time on, only professional training need to be arranged. Training pattern can be diversified, besides lectures, case study, tutorial, workshop, presentation and peer work can be tried, all training can be carried out with student-center learning ${ }^{[3]}$ model.

The goal for the first training to achieve is to help the trainee complete all the course implementation plans, all the assignments briefs and all the course evaluation plans during the training for all courses they are going to teach. For the second training, teachers who are newly engaged in the teaching of cooperative courses can be selected and sent to participate, and the training of teaching methods of professional courses can be arranged directly.

\subsection{To send teachers of multiple specialties to receive training at the same time}

College can cooperate with overseas partner with one specialty first, if the cooperation project works well, the cooperative specialties can be expended step by step to provide more overseas training opportunities for professional teachers. When sending teachers of several specialties to attend the training together, they can have classes together in the first week to receive the training of foreign vocational education concepts. In the following weeks, teachers of different specialties can be arranged to accept the training of their own fields in separate groups.

\subsection{Solidification and sharing of training results}

All teachers have their own tasks to fulfill when attend training, they need to submit training summary report. The report focuses on summarizing the teachers' understanding of foreign vocational education concepts, their various experiences in professional curriculum teaching, as well as the new classroom teaching design and evaluation methods for future teaching cooperation courses.

It is better for teachers to summarize the training at the same time, so that the content of the training can be noted clearly and the experience and feelings gained from the training can be recorded in time. For the report of academic value, 
can be published directly, a training report meeting can be held to share the achievements of the training in all teachers of the college.

\section{How to make better use of the resources of international partners}

\subsection{Utilization of partners' human resources}

\subsubsection{Make full use of the resources of teachers from the partner}

Through the adoption of the teaching assistant system, teachers teaching the same professional courses in the college can assume the teaching assistants of overseas teachers, so that assistant teachers have the opportunity to observe foreign teachers' courses in the whole process, and incorporate various good practices of foreign teachers' teaching into their own course teaching, so as to greatly improve their teaching level. In addition, foreign teachers can also be invited to attend the course teaching seminar, listen to their opinions on the handling of problems in the course teaching, and jointly discuss the cooperative course teaching plan.

\subsubsection{Give full play to the role of overseas quality verifiers}

Chinese teachers can make full use of the opportunity of foreign experts coming to the college for teaching quality verification ${ }^{[4]}$, and consult foreign experts on their own problems and perplexity in the implementation of the cooperative program. Through careful study of the assessment report of foreign experts, improving our work according to the action plan and insisting on continuous improvement ${ }^{[5]}$, the cooperative education project will to be running better and better.

4.1.3 Establish an interactive mechanism between Chinese and overseas teachers to strengthen the communication and cooperation between teachers

Through establishment of a working mechanism between the two partner colleges, Chinese teachers who encounter any difficulties in the implementation of the cooperative program teaching can directly send emails to foreign teachers for advice.

\subsection{Utilization of foreign teaching resources}

\subsubsection{Use of the outline}

The curriculum of vocational education in most developed countries can reflect its distinctive characteristics of vocational education. For example, the outline of British BTEC ${ }^{[6]}$ programs takes "learning outcomes" ${ }^{\text {"[7] }}$ as the basis of course evaluation and provide the "Assessment criteria" ${ }^{\text {"[8] }}$ to determine whether the outcomes have been achieved are clearly given in the outline. Each evaluation criterion of the syllabus begins with a verb, and the use of a different verb determines the level of achievement students can achieve in completing the task, as well as the specific knowledge they can master and the skills and technology they can develop after learning the course.

\subsubsection{Assignment briefs ${ }^{[9]}$}

Assignments are more often adopted to assess the vocational education courses, by completing the assignments, students have mastered the knowledge stipulated in the syllabus and cultivated different professional technologies and skills. By completing the assignments, students can produce evidence ${ }^{[10]}$ that they have gained the learning outcomes of the course, assignments is also an approach for teachers to carry out the assessment. Therefore, in the initial stage of the teaching of cooperative courses, if teachers can directly copy and use the course assignments designed by teachers taught the same courses from the partner college, it will greatly reduce the difficulty of cooperative courses teaching.

\subsubsection{Textbooks or reference books}

There are always no special textbooks specified for most of the advanced vocational programs, but teachers from the partner's college have always chosen some appropriate books as reference books for the course, it is always helpful to ask teachers from the partner colleges to recommend or buy some textbooks or reference books for us.

\subsubsection{Online teaching resources and learning resources}

Through the establishment of working mechanism between the partner colleges to ask the overseas partner teachers share their online teaching and learning resources with our teachers, the quality of cooperative project can be assured. If the cooperation lasts long enough, it is good to construct a special platform for project management to facilitate communication and exchanges between the Chinese and foreign teachers, teachers taught the same courses directly communicate to share experiences in teaching, discuss the problems discovered in the process of curriculum implementation. 


\section{The training effect comparison of different training models}

Through the form of questionnaire, we summarized the training effect comparison between the teachers selected who teach Sino-foreign cooperative courses (referred to as "relevant teachers") going abroad for professional training and the teachers selected who don't teach cooperative courses (referred to as "non-relevant teachers") going abroad for training.

Table 1. Training effect investigation

\begin{tabular}{|c|c|c|}
\hline Training effects & Relevant teachers & Non-relevant teachers \\
\hline Vision widening & Yes & Yes \\
\hline Learn new knowledge and ideas & Yes & Yes \\
\hline Whether the knowledge is applied in practical work & Yes & Not necessarily, no chance \\
\hline Harvest from training & Big, obvious, practical & Yes, poor practicality \\
\hline Whether teachers' own teaching ability has been improved & Significantly & Short-term improved \\
\hline $\begin{array}{c}\text { Whether teachers can become an active promoter of college } \\
\text { teaching reform }\end{array}$ & Mostly & Not sure \\
\hline
\end{tabular}

\section{Suggestions on overseas teacher training}

(1) Carrying out teacher's overseas training, professional teachers should be mainly selected together with a few administrative staff and English teachers.

(2) Colleges can achieve more by carrying out Sino-foreign international cooperative projects and introducing foreign advanced vocational education courses to promote teacher training.

(3) If the college hope to have the overseas vocational education programs and concept widely accepted and rooted in the college, there must be big enough number of staff to be trained overseas. The college needs to continually send teaching staff overseas to be trained each year as the cooperative projects going on. The fields of training don't need to be limited in the fields currently cooperated. After years of carrying out teachers training in this way, the fields of cooperation with overseas partners can be extended, it can also enables more teachers to receive training in the same vocational education methodology and concept, which is conducive to improving the overall level of the college teachers, promoting the college's teaching reform, and improving the overall level of the college's teaching management.

\section{References}

[1] Sadegh Abbasian, Ali Asghar Ravasi. The effect of antecedent-conditioning high-intensity interval training on BDNF regulation through PGC-1 $\alpha$ pathway following cerebral ischemia. Brain Research. 2020; 1729.

[2] Claire Fraser. Quality assurance-working as an Internal Verifier. Veterinary Nursing Journal. 2014; 1. https:// qualifications.pearson.com/content/demo/en/qualifications/btec-higher-nationals/manufacturing-operations-2019-rqf. html.

[3] Chen Na. Research on student-centered teaching model. Education modernization. 2019; A3: 256-257.

[4] Fan Rui, Pan Yonghui, Liu Yujuan. Construction and practice of teaching quality control system. Jiangsu education. 2009; 09.

[5] Sarah Caffyn. Development of a continuous improvement self-assessment tool. International Journal of Operations \& Production Management. 1999; 11.

[6] https://qualifications.pearson.com/content/demo/en/qualifications/btec-higher-nationals/manufacturing-operations2019-rqf.html.

[7] Gulsun Kurubacak. Building knowledge networks through project-based online learning: A study of developing critical thinking skills via reusable learning objects. Computers in Human Behavior. 2006; 6.

[8] Prevalence of irritable bowel syndrome in Chinese college and university students assessed using Rome III criteria. World Journal of Gastroenterology. 2010; 33.

[9] Rob van Roy, Bieke Zaman. Need-supporting gamification in education: An assessment of motivational effects over time. Computers \& Education. 2018.

[10] Sanders P. Evidence based assessment. British dental journal. 1996; 181(2): 49. 